\title{
A INCIDÊNCIA DE IMPOSTO SOBRE SERVIÇOS NOS SERVIÇOS BANCÁRIOS
}

\section{THE INCIDENCE OF SERVICES TAXES IN BANK SERVICES}

\author{
Cláudio Hiran Alves Duarte \\ Procurador do Município de Porto Alegre, RS, e \\ Coordenador do Movimento de Humanismo Concreto.
}

\begin{abstract}
Resumo: Estuda-se a incidência do Imposto Sobre Serviços nos serviços prestados pelos bancos e demais empresas financeiras, procurando-se apontar as objeções mais comuns que se levantam ao pagamento desse tributo.
\end{abstract}

$\mathrm{Na}$ introdução se procura demonstrar o contexto em que o estudo se insere, para depois se apresentarem alguns apontamentos sobre o Imposto Sobre Serviços, os serviços prestados pelos bancos e o plano de contas utilizado para registrá-los.
Na sequência é feita uma proposta de resolução, citando-se v. Precedente do e. Tribunal de Justiça do Estado do Rio Grande do Sul.

Palavras-chave: Direito Tributário. Imposto Sobre Serviços. Bancos. Princípio da Instrumentalidade. Leasing.

Abstract: The study of the incidence of services taxes in bank services and financial companies aims to indicate the most common objections pointed to the payment of the taxes shown previously. 
Revista da ESDM - 2016 - V. 2 - n. ${ }^{\circ} 3$

In the introduction, it is shown the context of the study and afterwards specific points related to services taxes, to bank services and to chart of accounts are presented. Then, a motion for a resolution is proposed quo- ting v. Precedent of e. Court of Justice of Rio Grande do SulState.

Key words: Tax Law. Services tax. Banks.

1. Introdução - 2. O imposto sobre serviços - 3. Os serviços bancários - 4. A nomenclatura utilizada pelas empresas financeiras - 5. A lista é taxativa - 6. Proposta de solução para os créditos tributários já formalizados ou judicializados - 7. Considerações Finais - 8. Notas -9. Referências bibliográficas

\section{INTRODUÇÃO}

Por que pagar tributos? Essa pergunta geralmente leva à conclusão sobre o quanto se paga de tributos, sem, infelizmente, nenhuma referência a quem paga ou sobre as condições necessárias à sociedade sem tributos.

É conhecida a famosa frase de Benjamim Franklin: “-Nada é mais certo neste mundo do que a morte e os impostos!", em tom de queixa. Poderia haver outro tom, mais condizente com a espécie humana, que dentre os mamíferos é a que nasce mais vulnerável e, por força disso, precisa de uma rede de cuidados indispensáveis à sobrevivência? Em quais condições o tom poderia ser outro? É o que se tenta descobrir neste pequeno texto, examinandose uma questão muitíssimo menos complexa: a incidência de ISS nos serviços bancários.

Primeiro o contexto em que se desenvolve essa questão abre o texto: quem paga tributos? Quem produz o conteúdo material da riqueza social ou, noutras palavras: quem produz as bases econômicas que sofrerão a incidência de tributos. Sobre eles é que pesa a carga tributária, eles são os contribuintes de fato. 
Sérgio Lessa (2005:p.28) identifica, resumidamente, quem são os contribuintes de fato:

"Na sociedade escravista, toda a riqueza era produzida pelo escravo, que convertia a natureza no 'conteúdo material da riqueza social'. Todas as outras classes sociais viviam da riqueza produzida pelo trabalho escravo. No feudalismo, os servos produziam o 'conteúdo material da riqueza' ao converterem a natureza nos bens indispensáveis à reprodução daquela sociedade. Todas as demais classes sociais viviam da riqueza oriunda da transformação da natureza pelos servos.

Na sociedade capitalista acontece o mesmo... A situação, simplificadamente (pois não incluiremos o capital bancário), é a seguinte:

a) O operário transforma a natureza e produz o conteúdo material da riqueza. Uma parte dessa riqueza é imediatamente convertida em mais-valia;

b) Uma parte da mais-valia é repassada aos capitalistas que atuam no comércio. O que dela resta após o pagamento dos assalariados dessa esfera é o lucro dos comerciantes;

c) Uma outra parte dessa mais-valia é convertida em impostos (quer diretamente, quando o próprio burguês os paga, ou indiretamente, quando quem os paga é o assalariado que recebeu a sua remuneração do burguês). Com esses impostos, os funcionários públicos recebem seus 'salários' e os capita- 
Revista da ESDM - 2016 - V. 2 - n. ${ }^{\circ} 3$

listas contratados pelo Estado (obras públicas, serviços etc.) tiram daí seu lucro e os recursos para pagarem seus empregados."

Percebe-se que o pagamento de tributos recai sempre sobre quem produz a riqueza material da sociedade, suas bases econômicas. Sobre isso ninguém discorda honestamente. Muitos doutrinadores na área do Direito Tributário chegam, inclusive, a utilizar a expressão mais-valia para questionar o cabimento da incidência de determinado tributo.

Os serviços bancários não produzem riqueza material alguma, apenas financiam, fomentam, a produção delas e são (i) necessários às relações de troca e (ii) de depósito e multiplicação das unidades de valor que as representam abstratamente. Mesmo assim, as empresas financistas se apropriam de parte significativa da riqueza socialmente produzida. Não é necessário o exame detalhado de balanços para constatar o fato notório de a lucratividade do setor bancário ser superior a da indústria, por exemplo.

São indispensáveis às relações medidas com base no valor de troca e estão em toda a parte, transformando em clientes de seus serviços as camadas sociais mais vulneráveis, através de empréstimos consignados ${ }^{1}$ concedidos, por exemplo, a beneficiários da previdência social que lhes transferem seus benefícios em suaves prestações.

Devem pagar tributos, em particular o objeto deste estudo, Imposto Sobre Serviços? Quais seriam as questões a serem dirimidas na relação tributária? As questões são numerosas e se renovam a cada dia, tornando-se necessário delimitá-las ao que cabe neste estudo. Por isso são resumidas basicamente às que surgem da objeção mais comum que aparece no tema: alguns serviços bancários (i) não estariam arrolados na lista anexa ao Decreto-Lei 406/1968 e, posteriormente, à Lei Complementar 116/2003, em razão de (ii) a nomenclatura utilizada para identificá-los ser diversa, o que 
(i.i) os retiraria do campo de incidência ou, caso superado esse óbice, (ii.i) dificultaria a defesa, motivando a nulidade da Certidão de Dívida Ativa (CDA).

O tema conta com repercussão geral reconhecida pelo e. Supremo Tribunal Federal no julgamento proferido em 13/08/2010, no RE 615580 RG / RJ, Relatora: Ministra ELLEN GRACIE:

TRIBUTÁRIO. IMPOSTO SOBRE SERVIÇOS ISS. ARTIGO 156, III, DA CONSTITUIÇÃO FEDERAL. LISTA DE SERVIÇOS. DECRETO-LEI 406/1968 E LC 116/2003. TAXATIVIDADE. EXISTÊNCIA DE REPERCUSSÃO GERAL.

Antes veio o v. Precedente proferido no julgamento do RE 71213/BA, Relator e. Ministro DJACI FALCAO, julgado em 11/05/1971:

IMPOSTO SOBRE SERVIÇOS. AS COMISSÕES SOBRE TITULOS DESCONTADOS, COBRADOS PELOS ESTABELECIMENTOS BANCARIOS, POR INTEGRAREM OPERAÇÃO DE DESCONTO FICAM SUJEITOS APENAS A TRIBUTAÇÃO FEDERAL. RECURSO CONHECIDO E PROVIDO.

E a Súmula 588/STF, aprovada na sessão plenária de 15/12/1976, com o seguinte enunciado: "O Imposto Sobre Serviços não incide sobre os depósitos, as comissões e taxas de desconto, cobrados pelos estabelecimentos bancários."

No âmbito do e. Superior Tribunal de Justiça o tema está condensado na Súmula 424: "É legítima a incidência de ISS sobre os serviços bancários congêneres da lista anexa ao DL n. o 406/1968 eà LC n. ${ }^{\circ}$ 56/1987...

O enunciado das súmulas não deixa dúvidas sobre a incidência do im- 
Revista da ESDM - 2016 - V. 2 - n. ${ }^{\circ} 3$

posto, ele incide sobre os serviços bancários. Permanece em aberto, contudo, o debate sobre a divergência de nomenclatura ou sobre quais serviços estariam dentro de seu campo de incidência.

Sobre esse desdobramento do tema deteve-se a c. Primeira Seção desse e. Tribunal, julgando, sob o regime previsto no artigo 543-C do CPC (recursos repetitivos), o REsp 1.111.234/PR e decidiu que a lista de serviços anexa ao Decreto-Lei 406/1968 e, posteriormente, a anexa à Lei Complementar n. ${ }^{\circ}$ 116/2003 são taxativas, mas admitem interpretação extensiva de cada item para que se possa enquadrar serviços correlatos aos expressamente previstos para a incidência do Imposto, prevalecendo, assim, o caráter real ("natureza") do serviço prestado e não a nomenclatura utilizada pelas empresas financeiras para identificá-lo.

Apesar de aparentemente superada no e. Superior Tribunal de Justiça a divergência sobre a nomenclatura (com a possibilidade de interpretação extensiva), ela prossegue com igual intensidade sob a alegação de haver suposto prejuízo à defesa.

Nos tópicos seguintes, procura-se apresentar a controvérsia e, após, uma proposta de resolução.

\section{O IMPOSTO SOBRE SERVIÇOS}

Quando se trata de tributos, a controvérsia de fundo é geralmente a mesma: por que pagá-los? Porque se pertence à sociedade e é preciso prover uma rede mínima de cuidados necessária à sobrevivência de seus membros. Mesmo as relações econômicas privadas, para se desenvolverem com segurança, liberdade e eficiência, precisam de garantias providas com recursos públicos vindos da arrecadação de tributos. Exemplo disso são a administração e a aplicação das normas de proteção aos consumidores, que, como se sabe, ao protegê-los, protegem antes o mercado e a livre concorrência con- 
tra as práticas abusivas ou predatórias.

Na sociedade antiga - ensina o i. Professor PAULO CALIENDO(2009):

“...dominada pela ideia de ordem. O indivíduo não existe fora da sociedade ('o homem fora da sociedade ou é um deus ou um bruto' - Política, Aristóteles). Desse modo, a tributação significava uma forma de manutenção da ordem natural, uma contribuição que cada indivíduo devia ao Estado em decorrência de um vínculo transcendental e não de uma obrigação legal...”.

Pagar tributos significava pertencer à sociedade, não estar fora dela como uma entidade divina.

Na sociedade moderna, pela mesma razão, mas com o acréscimo de o vínculo dar-se com o Estado Democrático de Direito e as necessidades poderem ser satisfeitas, inclusive, através de políticas fiscais, conforme registra o Professor PAULO CALIENDO na mesma obra.

Ensina, ainda, o i. Professor $^{2}$ que:

"No caso do direito brasileiro... dois são os elementos que devem ser destacados no texto constitucional: o caráter de delimitação e repartição de competências tributárias, em face do respeito ao exercício constitucional do poder de tributar e como proteção aos direitos fundamentais do contribuinte."

Com essa aproximação ao gênero (tributo), pode-se passar ao conceito legal de imposto, inscrito no artigo 16 do Código Tributário Nacional: "Imposto é o tributo cuja obrigação tem por fato gerador uma situação independente de qualquer atividade estatal específica relativa ao contribuinte". 
Na espécie em exame, o primeiro elemento a ser destacado no texto constitucional encontra-se no artigo 156, III, da Constituição Federal, onde há norma que diz competir aos Municípios e ao Distrito Federal instituir Imposto sobre "serviços de qualquer natureza, não compreendidos no artigo 155, II, definidos em lei complementar".

Em apertada síntese, esse tributo (que já foi de competência dos Estados na Constituição de 1891 e na de 1934) incide quando aatividade não configurar "... por si só, fato gerador de imposto de competência da União ou dos Estados"(BALEEIRO, 2000, p. 490-1), como o Imposto sobre Operações Financeiras (IOF), espécie mais próxima a objeto deste estudo -ao ser apresentado o aspecto material, voltar-se-á ao exemplo do IOF.

O Imposto Sobre Serviços tem como:

(i) Aspecto Material a prestação onerosa de serviços a terceiros - art. $1^{\circ}$ da LC 116/2003. A incidência do Imposto Sobre Serviços ocorre “...ainda que os serviços não se constituam como atividade preponderante do prestador.". Faz-se necessário um apontamento sobre a exclusividade do Imposto Sobre Serviços em sua relação com o Imposto sobre Operações Financeiras, dado que a sua incidência deve apartar-se das incidências de outros tributos. Para alguns doutrinadores seria:

“...a hipótese das entidades bancárias que têm por finalidade a concessão de crédito (operação afeta ao IOF); situação em que a abertura de conta corrente pertinente ao financiamento representa elemento integrante do mencionado negócio, não constituindo serviço distinto que possa sujeitar-se ao ISS." (SOARES DE MELLO, 2005, p.38).

No tópico abaixo se voltará ao tema, em razão de o item 15.02 da lista de serviços anexa à Lei Complementar 1116/2003 prever a incidência de Im- 
posto Sobre Serviços sobre a atividade de "Abertura de contas em geral, inclusive conta-corrente, conta de investimentos e aplicação e caderneta de poupança...";

(ii) Aspecto Temporal: a efetiva prestação do serviço. Há exceções imposta pela realidade, como nos casos dos serviços de espetáculos artísticos ou diversões públicas em que a incidência do imposto dá-se no momento da venda dos ingressos (naturalmente que a presunção não é absoluta, se o serviço não se efetivar - for cancelado o espetáculo- o imposto deverá ser devolvido). Na prestação de serviços bancários é preciso salientar que alguns são contínuos, prolongam-se no tempo, tais como os serviços de manutenção de cofres particulares e manutenção de contas. Nessas hipóteses, a apuração coincidirá com o período de pagamento desses serviços, geralmente mensal, e reger-se-á pela legislação do local em que forem prestados;

(iii) Aspecto Espacial: o território de determinado Município ou do Distrito Federal - art. $3^{\circ} \mathrm{c} / \mathrm{c}$ art. $4^{\circ}$ da LC 116/2003 - adiante se examinará em separado o local de incidência do Imposto Sobre Serviços na prestação do serviço de leasing financeiro, em razão de a controvérsia sobre o tema requerer um exame mais detido, na verdade, um estudo à parte;

(iv) Aspecto Pessoal: sujeito ativo (Municípios e Distrito Federal) e sujeito passivo (contribuinte prestador de serviços onerosos a terceiros, mesmo que a prestação de serviços não seja a sua atividade preponderante - art. 5. ${ }^{\circ}$ da LC 116/2003);

(v) Aspecto Quantitativo: base de cálculo (preço do serviço - art. $7^{\circ}$ da LC 116/2003) e alíquota (máxima: 5\% - art. 8. ${ }^{\circ}$, II, LC 116/2003 c/c art. 156, $\$ 3^{\circ}$, I, da CF; mínima: $2 \%$ - art. 88, incisos I e II, do Ato das Disposições Constitucionais Transitórias).

Parte do segundo elemento destacado pelo i. Professor PAULO CALIENDO ("proteção aos direitos fundamentais do contribuinte"), pode ser 
Revista da ESDM - 2016 - V. 2 - n. ${ }^{\circ} 3$

encontrado exemplificativamente no v. Precedente proferido pelo e. Superior Tribunal de Justiça nos seguintes termos:

"A dicção constitucional, como evidente, não autoriza que a lei complementar inclua no seu bojo atividade que não represente serviço e, a fortiori, obrigação de fazer, porque a isso corresponderia franquear a modificação de competência tributária por lei complementar, com violação do pacto federativo ..."

(STJ - AgRg no REsp 953.840-RJ, Relator Exmo. Sr. Ministro LUIZ FUX).

Da mesma forma, que:

"O conceito pressuposto pela Constituição Federal de serviço e de obrigação de fazer corresponde aquele emprestado pela teoria geral do direito, segundo o qual o objeto da prestação é uma conduta do obrigado, que em nada se assemelha ao dare, $\mathrm{cu}-$ jo antecedente necessário é o repasse a outrem de um bem preexistente, a qualquer título, consoante a homogeneidade da doutrina nacional e alienígena, quer de Direito Privado, quer de Direito Público."

(STJ - AgRg no REsp 953.840-RJ, Relator Exmo. Sr. Ministro LUIZ FUX).

Na prestação de serviços o objeto é, pois, a atividade, a ação, ainda que automatizada e envolvendo o fornecimento de mercadorias. Sobre este último aspecto consta no enunciado da Súmula n. ${ }^{\circ}$ 156/STJ: "A prestação de serviço de composição gráfica, personalizada e sob encomenda, ainda que en- 
volva fornecimento de mercadorias, está sujeita, apenas, ao ISS".

O fornecimento de um bem não deve causar estranheza, conforme salienta o e. Ministro EROS GRAU, em Voto proferido no julgamento do RE 547.245-SC ao decidir sobre a incidência de Imposto Sobre Serviços no leasing financeiro:

"Financiamento é serviço, sobre o qual o ISS pode incidir. É irrelevante, nas duas últimas hipóteses leasing financeiro e lease-back- existir uma compra. $\mathrm{O}$ fato é que toda e qualquer prestação de serviços envolve, em intensidades distintas, a utilização de algum bem."

Interessante anotar a diferença em relação às outras espécies, para que a distinção se apresente mais clara:

"O aspecto material da hipótese de incidência do ISS não se confunde com a materialidade do IPI e do ICMS. Isto porque: (i) excetuando as prestações de serviços de comunicação e de transporte interestadual e intermunicipal, o ICMS incide sobre operação mercantil (circulação de mercadoria), que se traduz numa 'obrigação de dar' (artigo 155, II, da CF/88), na qual o interesse do credor encarta, preponderantemente, a entrega de um bem, pouco importando a atividade desenvolvida pelo devedor para proceder à tradição; e (ii) na tributação pelo IPI, a obrigação tributária consiste num 'dar um produto industrializado' pelo próprio realizador da operação jurídica. 'Embora este, anteriormente, tenha produzido um bem, consistente em 
seu esforço pessoal, sua obrigação consiste na entrega desse bem, no oferecimento de algo corpóreo, materializado, e que não decorra de encomenda específica do adquirente' (José Eduardo Soares

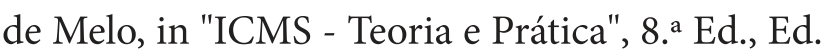
Dialética, São Paulo, 2005, pág. 65).”.

(STJ- REspREsp 888852 / ES, Rel. Min. LUIZ FUX).

Feitas as distinções é importante reter:

(i) $\mathrm{O}$ aspecto material da hipótese de incidência do ISS é a prestação dos serviços arrolados na lista anexaà Lei Complementar n. ${ }^{\circ}$ 116/2003 (antes na lista anexa ao Decreto-Lei 406/1968);

(ii) A lista de serviços admite interpretação extensiva de seus itens, para que prevaleça o caráter real (a "natureza") do serviço prestado;

(iii) O serviço não pode configurar, por si só, aspecto material de incidência de outro imposto, como, por exemplo, o Imposto sobre Operações Financeiras (IOF), espécie mais próxima a objeto deste estudo.

Com esses apontamentos básicos sobre o Imposto Sobre Serviços pode-se passar ao exame de sua incidência na prestação dos serviços objeto deste estudo.

\section{OS SERVIÇOS BANCÁRIOS}

A definição legal de empresa financeira se encontra no artigo 17 da Lei 
n. ${ }^{\circ} 4.595 / 64$, nos seguintes termos:

“Art. 17. Consideram-se instituições financeiras, para os efeitos da legislação em vigor, as pessoas jurídicas públicas ou privadas, que tenham como atividade principal ou acessória a coleta, intermediação ou aplicação de recursos financeiros próprios ou de terceiros, em moeda nacional ou estrangeira, e a custódia de valor de propriedade de terceiros."

Inegavelmente os bancos e as demais empresas financeiras são prestadores de serviços que se encontram, inclusive, regulados pelas normas do Código de Defesa do Consumidor (Lei 8078/1990), conforme dispõe o seu artigo $3 .^{\circ}, \S 2 .^{\circ}$ :

Art. 3. ${ }^{\circ}$ Fornecedor é toda pessoa física ou jurídica, pública ou privada, nacional ou estrangeira, bem como os entes despersonalizados, que desenvolvem atividade de produção, montagem, criação, construção, transformação, importação, exportação, distribuição ou comercialização de produtos ou prestação de serviços.

(...)

$\$ 2$. $^{\circ}$ Serviço é qualquer atividade fornecida no mercado de consumo, mediante remuneração, inclusive as de natureza bancária, financeira, de crédito e securitária, salvo as decorrentes das relações de caráter trabalhista. (sem grifos).

Estando essa atividade enquadrada na lista anexa à Lei Complementar n. ${ }^{\circ}$ 116/2003 (antes, na lista anexa ao Decreto-Lei 406/1968), que admite interpretação extensiva de seus itens, incidirá, em princípio, o Imposto 
Revista da ESDM - 2016 - V. 2 - n. ${ }^{\circ} 3$

Sobre Serviços.

Os itens 95 e 96 da lista anexa Decreto-Lei 406/1968 elencavam os serviços de:

95. Cobranças e recebimentos por conta de terceiros, inclusive direitos autorais, protestos de títulos, sustação de protestos, devolução de títulos não pagos, manutenção de títulos vencidos, fornecimentos de posição de cobrança ou recebimento e outros serviços correlatos da cobrança ou recebimento (este item abrange também os serviços prestados por instituições autorizadas a funcionar pelo Banco Central);

96. Instituições financeiras autorizadas a funcionar pelo Banco Central: fornecimento de talão de cheques; emissão de cheques administrativos; transferência de fundos; devolução de cheques; sustação de pagamento de cheques; ordens de pagamento e de crédito, por qualquer meio; emissão e renovação de cartões magnéticos; consultas em terminais eletrônicos; pagamentos por conta de terceiros, inclusive os feitos fora do estabelecimento; elaboração de ficha cadastral; aluguel de cofres; fornecimento de segunda via de avisos de lançamento de extrato de contas; emissão de carnês (neste item não está abrangido o ressarcimento, a instituições financeiras, de gastos com portes do Correio, telegramas, telex e teleprocessamento, necessários à prestação dos serviços).

Na legislação atual, Lei Complementar 116/2003, o item 15 da lista ane- 
xa enumera os serviços que se encontram dentro do campo de incidência do tributo.

Dentre os itens que requerem algumas observações destacam-se três: 15.02, 15.09 e 15.15, feitas apenas para exemplificar a existência de controvérsia sobre temas que não se encontram dentro da objeção relativa à diferença de nomenclatura atribuída aos serviços registrados na contabilidade das empresas financeiras (que segue o COSIF - Plano Contábil das Instituições do Sistema Financeiro Nacional) e os arrolados na lista de serviços anexa à Lei Complementar 116/2003. Mesmo quando a nomenclatura é a mesma, surgem questões a dirimir.

No primeiro exemplo (abertura de contas em geral, item 15.02 da lista) aborda-se a relação com o Imposto sobre Operações Financeiras e exemplifica-se a existência de atividades na lista de serviços anexa à Lei Complementar 116/2003 que não apareciam expressamente na anexa ao DecretoLei n. ${ }^{\circ} 406 / 68$.

No segundo exemplo (leasing financeiro, item 15.09 da lista), demonstra-se que, apesar de superada a discussão sobre a incidência do Imposto Sobre Serviços, permanece o debate sobre onde ele deve incidir: no território com alíquota de $2 \%$, geralmente pretendido pelas empresas financeiras, ou noutro em que a fiscalização tributária tenha apurado a efetiva prestação desse serviço.

No terceiro exemplo (item 15.15) faz-se uma distinção entre uma atividade meio (mero depósito para realizar uma operação financeira que provavelmente sofrerá a incidência de IOF) dos serviços de depósitos propriamente ditos (p. ex.: depósito identificado), sujeitos à incidência de Imposto Sobre Serviços.

a) ABERTURA DE CONTAS EM GERAL

O serviço de "Abertura de contas em geral, inclusive conta-corrente, con- 
Revista da ESDM - 2016 - V. 2 - n. ${ }^{\circ} 3$

ta de investimentos..." não estava expressamente previstos nos itens 95 e 96 da lista de serviços anexa ao Decreto-Lei n. ${ }^{\circ}$ 406/68.

Em princípio, abrir uma conta investimento ou abrir uma conta para o fim de sacar valores obtidos através de financiamento seria uma atividade inerente ao próprio financiamento, não constituiria prestação de serviço (distinto) e, portanto, o preço cobrado por essa atividade não poderia sofrer a incidência do Imposto Sobre Serviços. Ela seria uma operação de crédito, de caráter financeiro ("natureza"), passível da incidência do Imposto sobre Operações de Crédito apenas.

Mas seria mesmo assim? Será que uma conta investimento serve apenas a esse fim: realizar uma operação financeira? Ou dito de outra maneira: a abertura de conta seria imprescindível à realização de um investimento? Por que seria imprescindível?

Os bancos afirmam que sim em razão de os sistemas operacionais que utilizam a exigirem. Segundo eles, o ato simples de entregar valores e pronunciar duas palavras, “- Quero investir.”, não seria exequível, antes teria de ser aberta uma conta para que os devidos registros no Plano de Contas fossem feitos, não lhes bastando a simples entrega ou transferência de valores destinados à operação financeira (investimento).

Com o devido respeito às opiniões em contrário, não se pode aceitar esse argumento dos bancos, sob pena de se transferir a eles a definição do que é atividade-meio e atividade-fim, transferindo-lhes, em última instância, a definição do campo de incidência do Imposto Sobre Serviços. O plano de contas ou o sistema operacional ocuparia o lugar e a função da lista de serviços. Isso seria inadmissível.

A abertura e a manutenção de contas não são atividades-meio (imprescindíveis) à realização de um investimento. Este pode realizar-se, à toda evidência, sem a abertura de conta, com a simples entrega dos valores que serão investidos. 
Ocorre o mesmo que se passa, por exemplo, com os serviços que se encontram junto aos prestados pelas operadoras de TV a Cabo, tributáveis a título de Imposto Sobre Serviços, conforme v. precedente proferido pelo e. Superior Tribunal de Justiça:

"...aos serviços prestados pelas operadoras de TV a Cabo - sobre os quais incide o ICMS - agregam-se outros serviços acessórios, como os de assistência técnica, de instalação de equipamentos, mudança na seleção de canais, habilitação de decodificador e de ponto extra, que não se confundem com os de telecomunicação propriamente dito e sobre os quais deve incidir o imposto municipal - ISS, na forma do Decreto-lei 406/68, item 21 da Lista de Serviços - 'Assistência Técnica"'.

(STJ - REsp 710.744/MG, Relatora E.. Min. Eliana Calmon, Segunda Turma, julgado em 07/02/06).

A abertura e a manutenção de contas são serviços que produzem diversas utilidades aos seus usuários, tais como: saques, transferências de valores, realização de pagamentos diversos etc. Por essa razão: “...não mais se caracterizam como atividades condicionantes da concretização de um fim, mas demarcam, ao revés, o próprio objeto colimado. Nesses casos, a razão última dessas ações é a sua própria produção como utilidade, para terceiros."(BARRETO, 1996, p.81-2)

Mesmo as contas investimentos, como é notório, não se resumem ao fim investimento. Enquanto os valores permanecem nelas, aplicados em operações financeiras, os titulares dessas contas podem desfrutar de outras utilidades (saques, transferência de valores etc.). Não há razão, portanto, para a abertura dessas contas ser considerada uma mera atividade meio (indispensável) à realização de uma operação financeira. 
Não cabe aos bancos definir o que é atividade-meio e atividade-fim, substituindo a realidade. Não se pode transferir-lhes a definição do campo de incidência do Imposto Sobre Serviços, subordinando a interpretação da lista de serviços ao plano de contas ou ao sistema operacional utilizado por eles.

\section{b) LEASING FINANCEIRO}

Merece destaque o aspecto espacialdefinidor do sujeito ativo na prestação dos serviços de leasing financeiro (item 15.09 da lista), em razão da v. decisão proferida pelo e. STJ no julgamento do Resp n. ${ }^{\circ}$ 1.060.210-SC, sob o rito do art. 543-C, do Código de Processo Civil.

A v. decisão assenta que:

“...tanto na vigência do DL 406/68 quanto na vigência da LC 116//2003, o núcleo da operação de arrendamento mercantil, o serviço em si, que completa a relação jurídica, é a decisão sobre a concessão, a efetiva aprovação do financiamento.",

“...assim entendido o local onde se comprove haver unidade econômica ou profissional da instituição financeira com poderes decisórios suficientes à concessão e aprovação do financiamento - núcleo da operação de leasing financeiro e fato gerador do tributo...."

E, supostamente para não deixar dúvidas sobre onde fica esse local, indica-o geograficamente nos seguintes termos:

"As grandes empresas de crédito do País estão sediadas ordinariamente em grandes centros financeiros de notável dinamismo, onde centralizam os poderes decisórios e estipulam as cláusulas contratu- 
ais e operacionais para todas suas agências e dependências."

Para alguns a controvérsia restaria dirimida no sentido de o local da prestação do serviço lesaing financeiro ser o da "sede" da empresa financeira, que geralmente se encontra "em grandes centros financeiros".

Com o devido respeito, além de apressados, os que compartilham desse entendimento transformam o Direito em sistema autopoiético limitado (além de normativamente fechado, ele também seria cognitivamente fechado), dando razão à ácida crítica do Ministro EROS GRAU (1996:p.21) a N. LUHMANN: “...o direito ... trata ... apenas de problemas internos a si próprio, de seus próprios problemas....."

Para os que acreditam que o Direito é mais do que isso e precisa tratar dos problemas que justificam a sua existência (p.ex.: reduzir as desigualdades sociais e regionais - artigos $3 .^{\circ}$, III, e 170, VII, da CF) a v. decisão aponta para outro sentido, ao estabelecer como critério identificador do local o poder decisório para completar a relação jurídica materializada no leasing financeiro.

Em seu voto, o Ministro Herman Benjamin registra o debate e salienta o fundamento que conduz à conclusão, sintetizando as mais de setenta folhas que registram o julgado nos seguintes termos:

(i) Estabelecimento prestador não se confunde com sede ou domicílio fiscal;

(ii) No leasing financeiro o núcleo do serviço prestado é o financiamento (STF: RE 547.245/SC e o RE 592.905/SC);

(iii) Como:

"O contrato de leasing financeiro é um contrato complexo no qual predomina o aspecto financeiro, 
tal qual assentado pelo STF quando do julgamento do RE 592.905/SC ... há se concluir que, tanto na vigência do DL 406/68 quanto na vigência da LC 116//203, o núcleo da operação de arrendamento mercantil, o serviço em si, que completa a relação jurídica, é a decisão sobre a concessão, a efetiva aprovação do financiamento.";

(iv) O serviço:

“...é efetivamente prestado onde a relação é perfectibilizada, assim entendido o local onde se comprove haver unidade econômica ou profissional da instituição financeira com poderes decisórios suficientes à concessão e aprovação do financiamento núcleo da operação de leasing financeiro e fato gerador do tributo.";

(v) É a presença de poder decisório o critério eleito para definir o local em que é devido o Imposto Sobre Serviços.

Simples e claro: como a jurisprudência anterior do e. STJ era insuficiente para gerar segurança jurídica, porque não indicava onde ocorria o fato gerador, decidiu-se que ele ocorre onde há poder decisório para a “...efetiva aprovação do financiamento".

Ocorre que por pelo menos duas razões Sísifo recomeça seu trabalho no tema.

Primeira: onde está o poder decisório para a “...efetiva aprovação do financiamento"?

Tanto pode estar na "sede" da empresa financeira, quanto no estabelecimento prestador, que não se confunde com aquela e está definido no artigo 4. ${ }^{\circ}$ da Lei Complementar 116/2003: 
"Art. $4{ }^{\circ}$ Considera-se estabelecimento prestador o local onde o contribuinte desenvolva a atividade de prestar serviços, de modo permanente ou temporário, e que configure unidade econômica ou profissional, sendo irrelevantes para caracterizá-lo as denominações de sede, filial, agência, posto de atendimento, sucursal, escritório de representação ou contato ou quaisquer outras que venham a ser utilizadas."

Havendo poder decisório no estabelecimento prestador para aprovar o financiamento, nesse local é devido o Imposto Sobre Serviços.

Como é notório, as unidades, filiais, agências, postos de atendimento, sucursais, escritórios de representação ou contatos ou quaisquer outras que venham a ser utilizadas pela empresa financeira, geralmente se encontram onde é oferecido o serviço de leasing financeiro ou onde está o tomador do serviço.

Volta-se, assim, ao que havia antes e estava consolidado na jurisprudência do e. Superior Tribunal de Justiça (que se pretendia superar): onde ocorre o fato gerador? Onde está o poder decisório. E onde está o poder decisório?

Segunda razão: qual seria mesmo o poder decisório da empresa financeira?Qual seria a extensão desse poder decisório?

Naturalmente que é exclusiva da empresa financeira a decisão de colocar no mercado o serviço de leasing e ofertá-lo aos potenciais clientes. Feita a oferta, seu "poder decisório" para liberar o financiamento simplesmente cessa, face ao disposto no artigo 30 do Código de Defesa do Consumidor (Lei 8078/1990):

Art. 30. Toda informação ou publicidade, suficien- 
temente precisa, veiculada por qualquer forma ou meio de comunicação com relação a produtos e serviços oferecidos ou apresentados, obriga o fornecedor que a fizer veicular ou dela se utilizar e integra o contrato que vier a ser celebrado.

Como os serviços de leasing financeiros também são regulados pelas normas do Código de Defesa do Consumidor, conforme dispõe o seu artigo 3. ${ }^{\circ}$, $\$ 2 .{ }^{\circ}$ :

Art. $3 .^{\circ} \ldots$

(...)

$\$ 2 .^{\circ}$ Serviço é qualquer atividade fornecida no mercado de consumo, mediante remuneração, inclusive as de natureza bancária, financeira, de crédito e securitária, salvo as decorrentes das relações de caráter trabalhista. (sem grifos).

Por conseguinte, a vontade que externa o poder decisório para aprovar o financiamento não é absoluta e pode ser facilmente suprida judicialmente, bastando que o cliente atenda aos requisitos pressupostos na oferta e procure o Judiciário para supri-la.

Nesse sentido, mesmo julgando temas relativos a contratos consensuais, bilaterais, vem decidindo o e.STJ:

\section{(...)}

...trata-se de uma típica relação de consumo, conforme já reconhecido pela jurisprudência desta Corte (Súmula 297/STJ) e do Supremo Tribunal Federal (ADIN n. ${ }^{\circ}$ 2591).

Consequentemente, a postura do banco requerido, 
ora recorrido, devia respeito aos postulados do Código de Defesa do Consumidor (CDC).

E a conduta unilateral do banco recorrido, encerrando abruptamente as contas mantidas há longos anos, sem qualquer justificativa razoável, representou uma prática abusiva, conforme corretamente reconhecido pela sentença, violando as regras do art. 39, incisos II e IX, do CDC...

(...)

(STJ- REsp 1.277.762 - SP, Em. Min. PAULO DE TARSO SANSEVERINO).

Eainda:

(...)

Outrossim, mesmo que o planejamento estatal seja meramente indicativo para o setor privado (art. 174 da CF/88), deve-se considerar o atual movimento do governo brasileiro no sentido da inclusão bancária, de modo que a extinção imotivada do contrato de conta-corrente atenta contra a própria função social do contrato.

(...)

(STJ- REsp 1.277.762 - SP, Em. Min. NANCY ANDRIGHI).

A empresa financeira não pode simplesmente deixar de contratar ou interromper a relação contratual. Estando assim limitado o poder decisório da empresa financeira nos contratos consensuais, que dizer nos contratos de adesão, previstos no artigo 54 do CDC, em que se contratam os serviços de leasing? 
Revista da ESDM - 2016 - V. 2 - n. ${ }^{\circ} 3$

Parece que se pode imaginá-lo bem mais limitado e mais fácil de ser suprida judicialmente a vontade que o manifesta.

Pois bem, em qual local ela poderia ser suprida? A critério do consumidor que atendesse à proposta, no foro de seu domicílio (artigo 101, I, CDC), o que equivale a dizer: no domicílio do tomador (= consumidor), onde se efetivaria o financiamento e, portanto, o fato gerador do ISS.

Novamente volta-se ao começo. A v. decisão proferida no julgamento do Resp n. ${ }^{\circ}$ 1.060.210-SC, sob o rito do art. 543-C, do CPC, estabelece que o local em que deve ser recolhido o ISS é o do estabelecimento prestador com poder decisório para aprovar o financiamento.

O estabelecimento prestador está definido no artigo $4^{\circ}$ da Lei Complementar 116/2003 e, geralmente, encontra-se no local em que o serviço é ofertado aos seus potenciais consumidores (domicílio do tomador).

O poder decisório para aprovar o financiamento, por sua vez, não é absoluto, seu exercício encontra-se condicionado à observância das normas inscritas no Código de Defesa do Consumidor. Em princípio ele se esgota com a oferta, podendo ser suprida judicialmente a vontade que o manifesta. É possível antever que, na maioria das vezes, ela será suprida no foro do domicílio do tomador (= consumidor), conforme facultado no artigo 101, I, do Código de Defesa do Consumidor.

\section{c) DEPÓSITOS}

Com a lista anexa à Lei Complementar 116/2003, é preciso distinguir depósito (mera entrega de valores, por exemplo, para realizar uma operação financeira sujeita a IOF) dos serviços relacionados a depósitos (previstos no item 15.15, p. ex.: depósitos identificados), compatibilizando-se, assim, o enunciado da Súmula 588/STF, de 15/12/1976 (“O Imposto Sobre Serviços não incide sobre os depósitos....”), enquanto o e. Supremo não o reexaminálo. 
Outros tribunais já vêm fazendo essa compatibilização, conforme se pode verificar no v. Precedente proferido pelo e. Superior Tribunal de Justiça no julgamento do AgRg em REsp 182.036 - ES, Relator E. Ministro HERMAN BENJAMIN, julgado em 31/05/2012:

(...)

Conquanto não seja clara a redação do enunciado sumular no 588 , do Excelso Supremo Tribunal Federal, a não incidência tributária do ISSQN se deve apenas àquelas comissões e tarifas que sofram incidência do IOF. Isto é, incidindo IOF, não há que se falar em incidência de ISSQN, já que os 02 (dois) tributos possuem hipóteses de incidência tributária completamente distintas: o primeiro (IOF) possui por fato gerador as operações financeiras, que são atividades típicas dos bancos, enquanto a hipótese normativa do ISSQN são os demais serviços prestados pelas Instituições Financeiras. Desse modo, não há que se falar em bitributação...

(...)

O v. Precedente é elucidativo e indica com precisão o critério à tomada de outras decisões: não incidindo o Imposto sobre Operações Financeiras (IOF), incidirá o Imposto Sobre Serviços.

\section{A NOMENCLATURA UTILIZADA PELAS EMPRESAS FINAN- CEIRAS - COSIF}

Feitas essas observações sobre os itens que despertam maior atenção ao objeto deste estudo (itens 15.02, 15.09 e 15.15), pode-se prosseguir com o 
Revista da ESDM - 2016 - V. 2 - n. ${ }^{\circ} 3$

exame da principal objeção que as empresas financeiras fazem à incidência do tributo sobre a prestação de seus serviços: alguns serviços não estariam arrolados na lista em razão de a nomenclatura utilizada para identificá-los ser diversa, o que os retiraria do campo de incidência ou, caso superado esse óbice, dificultaria a defesa.

Os serviços arrolados na lista aparecem na contabilidade das empresas financeiras com a nomenclatura utilizada no COSIF -no Plano Contábil das Instituições do Sistema Financeiro Nacional- criado em 29 de dezembro de 1987 para unificar os diversos planos contábeis existentes à época e uniformizar os procedimentos de registro de demonstrações financeiras.

O COSIF está dividido em quatro capítulos (demasiado longos para serem reproduzidos aqui) que podem ser encontrados no seguinte sítio: http://www4.bcb.gov.br/NXT/gateway.dll? $f=$ templatese $f n=$ default.htmevi $d=n m s$ DenorCosif:idvDenorCosif

Citam-se a título exemplificativo as seguintes contas:

RENDAS DE EMPRÉSTIMOS - COSIF 7.1.1.5.00-6

$\mathrm{Na}$ conta são contabilizadas as tarifas de abertura de crédito relativas às operações ativas realizadas pelo banco, nas diversas carteiras.

RENDAS DE COBRANÇA - COSIF 7.1.7.40.00-7

Registram as rendas de tarifas, portes e comissões por prestação de serviços de cobrança, que constituam receita efetiva da instituição, no período.

RENDAS DE OUTROS SERVIÇOS - COSIF 7.1.7.90.00-3

Consistem nas rendas de tarifas, portes e comissões cobrados pela prestação de serviços diversos, para 
cuja escrituração não exista conta adequada, exigindo vários subtítulos de uso interno.

OUTRAS RENDAS OPERACIONAIS - COSIF 7. 1.9.99.00-9

Contabilizam todas as receitas bancárias sem título específico.

RECUPERAÇÃO DE ENCARGOS E DESPESAS COSIF 7.1.9.30.00-6

Registram os valores recebidos pelos bancos referentes a despesas pagas por eles anteriormente.

Não é necessário um grande esforço para se perceber que a maior parte das receitas é contabilizada nas contas: rendas de outros serviços (COSIF 7.1.7.90.00-3), outras rendas operacionais (COSIF 7.1.9.99.00-9) e recuperação de encargos e despesas (COSIF 7.1.9.30.00-6), o que torna difícil à fiscalização tributária identificar o verdadeiro caráter do serviço. Difícil senão quase impossível, dado o emaranhado de códigos.

Além disso, na maioria das vezes, a mesma atividade aparece com um nome na lista de serviços e com outro no COSIF, dando margem à seguinte objeção levantada pelas empresas financeiras: ela estaria fora do campo de incidência ou, no mínimo, a nomenclatura diferente dificultaria a defesa e, como consequência nos casos de o tributo já ter sido formalizado, a Certidão de Dívida Ativa (CDA) seria nula.

Seria aceitável tal objeção?Nos tópicos seguintes tenta-se demonstrar que não.

\section{A LISTA É TAXATIVA}

Seguramente a lista de serviços é taxativa. Nem poderia ser diferente, 
Revista da ESDM - 2016 - V. 2 - n. ${ }^{\circ} 3$

considerando-se que a legalidade tributária é absoluta e distingue-se do Princípio da Legalidade previsto no artigo $5 .^{\circ}$ da Constituição Federal pelo fato de não ser relativa (art. 150, I, CF e art. 97 do CTN). Ela veda a delegação de aspectos ou a integração normativa, conforme assentado na jurisprudência, p. ex.: no REsp724.779-RJ, Relator E. Ministro LUIZ FUX, julgado em 12/09/2006 nos seguintes termos:

\section{(...)}

...realçado no campo tributário pelo art. 150, I, da Carta Magna, o princípio da legalidade consubstancia a necessidade de que a lei defina, de maneira absolutamente minudente, os tipos tributários. Esse princípio edificante do Direito Tributário engloba o da tipicidade cerrada, segundo o qual a lei escrita - em sentido formal e material - deve conter todos os elementos estruturais do tributo, quais sejam: a hipótese de incidência - critério material, espacial, temporal e pessoal -, e o respectivo consequente jurídico, tal qual determinado pelo art. 97, do CTN...

\section{(...)}

Não se pode, pois, admitir que a analogia ou a interpretação extensiva traga para dentro da tipicidade cerrada serviços que se encontram fora dela, mas se pode admitir que para compreender e fazer prevalecer o real caráter ("natureza") dos serviços prestados -no confronto com a nomenclatura utilizada pelas empresas financeiras- a analogia e a interpretação extensiva sejam utilizadas. Essa distinção é de extrema importância e encontra-se consolidada na jurisprudência, conforme se pode constatar: 
A Primeira Seção deste Tribunal Superior, ao julgar o REsp 1.111.234/PR, sob o regime dos regime do art. 543-C do CPC, reconheceu que a lista de serviços anexa ao Decreto-Lei 406/1968 e à Lei Complementar 116/2003, para fins de incidência do ISS sobre serviços bancários, é taxativa, admitindo-se, porém, uma leitura extensiva de cada item, para que se possam enquadrar os serviços correlatos nos previstos expressamente, de modo que prevaleça a efetiva natureza do serviço prestado e não a denominação utilizada pela instituição financeira.

(...)

(STJ - AgRg no REsp 1311856 / SP, Relator E. Ministro SÉRGIO KUKINA, julgado em 15/10/2013). (...)

A lista de serviços anexa ao Decreto-lei n. ${ }^{\circ} 406 / 68$, que estabelece quais serviços sofrem a incidência do ISS, comporta interpretação extensiva, para abarcar os serviços correlatos àqueles previstos expressamente, uma vez que, conforme ponderado pela ilustre Ministra Eliana Calmon, se assim não fosse, ter-se-ia, pela simples mudança de nomenclatura de um serviço, a incidência ou não do ISS.

(...)

(Resp 325344/PR, Rel. Ministra ELIANA CALMON, Rel. p/ Acórdão Ministro FRANCIULLI NETTO, julgado em 07/11/2002).

A interpretação extensiva é uma necessidade para que prevaleça o real 
Revista da ESDM - 2016 - V. 2 - n. ${ }^{\circ} 3$

caráter ("natureza") dos serviços prestados e não se corra o risco de transferir aos bancos a delimitação do campo de incidência do Imposto Sobre Serviços. Negar a interpretação extensiva exigiria um elevado grau de ingenuidade, conforme adverte o E. Ministro HERMAN BENJAMIN:

\section{(...)}

Admitir a necessidade de identidade total dos nomes utilizados pelas Instituições Financeiras com aquelas atividades descritas pela Lista de Serviços, permitiria burla à Administração Tributária, porquanto bastaria a alteração de um nome para fugir da incidência fiscal. Precedentes do Egrégio Superior Tribunal de Justiça.

(STJ - AgRg em REsp 182.036 - ES, Relator E. Ministro HERMAN BENJAMIN, julgado em 31/05/2012).

O e. Tribunal de Justiça do Estado do Rio Grande do Sul profere vv. Precedentes sobre o tema, dirimindo com elevada sabedoria a controvérsia e examinando com profundidade a matéria. Serve de exemplo o v. Precedente proferido no julgamento da Apelação Cível n. ${ }^{\circ} 70048346225$, Relator E. Desembargador RICARDO TORRES HERMANN, julgado em 25/09/2013:

“...entende-se que os serviços prestados pelos bancos e que não constituem operações tributadas pelo IOF, estão genericamente incluídos na Lista de Serviços do ISS, já que não é razoável imaginar que a referida Lista pudesse compreender, de forma cabal e literal, todas as nomenclaturas e expressões empregadas na atividade bancária para efeito de 
lançamento contábil. Até porque, a evolução da atividade bancária é mais constante do que a atividade legislativa, de modo que a interpretação literal, no caso, levaria à ausência de exação sobre certos serviços pelo simples motivo de apresentarem denominação distinta. Assim, o que importa é que a natureza do serviço esteja prevista na lista anexa à lei complementar."

O real caráter ("natureza") dos serviços prestados é simples matéria de prova que no caso dos créditos tributários já formalizados ou judicializados conta com presunção (relativa) de certeza inerente à Certidão de Dívida Ativa, nos termos do artigo 204 do Código Tributário Nacional:

Art. 204. A dívida regularmente inscrita goza da presunção de certeza e liquidez e tem o efeito de prova pré-constituída.

Parágrafo único. A presunção a que se refere este artigo é relativa e pode ser ilidida por prova inequívoca, a cargo do sujeito passivo ou do terceiro a que aproveite.

A presunção pode ser facilmente ilidida mediante a demonstração de se tratar de (i) atividade sujeita à incidência de Imposto sobre Operações Financeiras (IOF) ou (ii) sem correlação com a lista de serviços, circunstâncias que a excluiriam do campo de incidência do Imposto Sobre Serviços, ou, ainda, (iii) demonstrando-se que por algum motivo relevante a defesa restou prejudicada, circunstância que levaria à nulidade da Certidão de Dívida Ativa (CDA).

\section{PROPOSTA DE SOLUÇÃO PARA OS CRÉDITOS TRIBUTÁRIOS JÁ FORMALIZADOS OU JUDICIALIZADOS}


Revista da ESDM - 2016 - V. 2 - n. ${ }^{\circ} 3$

A lista de serviços anexa à Lei Complementar 116/2003 é bem mais minuciosa e abrangente que a lista anexa ao Decreto-lei n. ${ }^{\circ} 406 / 68$, conforme registrado acima, o que diminui enormemente a primeira objeção levantada pelas empresas financeiras à tributação dos seus serviços.

Com o nível de detalhamento existente na nova lista é mais difícil sustentar que os serviços não estariam arrolados nela (objeção “i”) e, com a possibilidade consagrada na jurisprudência de a interpretação ser extensiva, torna-se improdutivo sustentar que a nomenclatura diversa os retiraria do campo de incidência do Imposto Sobre Serviços (objeção “ii”), restando aos bancos a alegação de prejuízo à defesa (objeção "ii.i”), o que motivaria a nulidade da Certidão de Dívida Ativa (CDA).

É a alegação que mais aparece na causa de pedir dos bancos, conforme se pode verificar no seguinte caso prático julgado pelo e. Tribunal de Justiça do Rio Grande do Sul, proferido no julgamento do recurso de apelação n. ${ }^{\circ} 70048346225$, nos seguintes termos:

\section{(...)}

Nessa ordem de coisas, entende-se que os serviços prestados pelos bancos e que não constituem operações tributadas pelo IOF, estão genericamente incluídos na Lista de Serviços do ISS, já que não é razoável imaginar que a referida Lista pudesse compreender, de forma cabal e literal, todas as nomenclaturas e expressões empregadas na atividade bancária para efeito de lançamento contábil. Até porque, a evolução da atividade bancária é mais constante do que a atividade legislativa, de modo que a 
interpretação literal, no caso, levaria à ausência de exação sobre certos serviços pelo simples motivo de apresentarem denominação distinta. Assim, o que importa é que a natureza do serviço esteja prevista na lista anexa à lei complementar.

(...)

A solução dada à lide pelo e. Tribunal de Justiça do Rio Grande do Sul resume o que vem sendo exposto e serve de proposta para a solução definitiva das controvérsias sobre o tema.

À douta proposta que o v. Precedente apresenta se poderia agregar a preocupação manifestada pelo e. Superior Tribunal de Justiça em efetivar o Princípio da Instrumentalidade: apenas na hipótese de nulidade insanável ou de comprovado dano à defesa é que se poderia cogitar de nulidade da Certidão de Dívida Ativa (CDA). Nesse sentido:

PROCESSUAL CIVIL E TRIBUTÁRIO - RECURSO ESPECIAL - EXECUÇÃO FISCAL - CDA - REQUISITOS ...

1. A nulidade da CDA não deve ser declarada por eventuais falhas que não geram prejuízos para o executado promover a sua a defesa, informado que é o sistema processual brasileiro pela regra da instrumentalidade das formas (pasdesnullitéssansgrief), nulificando-se o processo, inclusive a execução fiscal, apenas quando há sacrifício aos fins da Justiça.

2. Recurso especial provido

(STJ - REsp 840.353/RS, Rel. E. Ministra ELIANA

CALMON, DJe de 07/11/2008). 
Revista da ESDM - 2016 - V. 2 - n. ${ }^{\circ} 3$

Sugere-se que a nulidade da Certidão de Dívida Ativa (CDA) somente possa ser cogitada nos casos em que não preenchidos os requisitos indispensáveis à defesa, previstos no artigo 202 do Código Tributário Nacional, ou comprovados quaisquer danos à defesa.

\section{CONSIDERAÇÕES FINAIS}

Ao se apresentar o contexto em que se insere este texto procurou-se demonstrar que a pesada carga tributária é suportada historicamente por quem produz a riqueza social. Notadamente o peso aumenta à medida que mais diretamente se está envolvido na produção.

Conjugado a esse fato, $\mathrm{o}$ ato de pagar tributos torna-se um tormento e somente pode ser lembrado em tom de queixa, como faz Benjamim Franklin em sua famosa frase citada na introdução.

Poderia haver outro tom? Em quais condições? Mesmo sem a pretensão de responder a questões tão complexas é possível ver nas lições do i. Professor PAULO CALIENDO (2009), que relaciona a proteção aos direitos fundamentais do contribuinte com a responsabilidade ética inerente à existência em sociedade, um belo caminho para a resposta e, sem imputar responsabilidade alguma a esse i. Professor, é possível afirmar que tão ou mais importante que a redução da carga tributária é a necessidade de dividi-la com mais equidade.

No plano jurídico não se questiona o direito de os bancos e as demais empresas financeiras pretenderem pagar menos tributos, mas se questiona as objeções que levantam ao pagamento do Imposto Sobre Serviços porque destituídas de razões sólidas.As objeções que levantam podem ser facilmente rebatidas, conforme demonstrado nos capítulos anteriores, considerando-se que: 
a) Deve prevalecer o real caráter dos serviços prestados, não a nomenclatura utilizada para registrálos no plano de contas utilizado pelas empresas financeiras (COSIF);

b) Os serviços prestados pelas empresas financeiras que se encontram descritos na lista de serviços anexa à Lei Complementar n. ${ }^{\circ} 116 / 2003$ (antes na lista anexa Decreto-lei n. ${ }^{\circ}$ 406/68) estão dentro do campo de incidência do Imposto Sobre Serviços, a menos que, é evidente, constituam, por si só, atividade passível da incidência do Imposto sobre Operações Financeiras;

c) A lista de serviços pode receber interpretação extensiva de seus itens;

d) Não se pode substituir a realidade para definir o que é atividade-meio e atividade-fim. Não se pode transferir aos bancos a definição do campo de incidência do Imposto Sobre Serviços, subordinandose a interpretação da lista de serviços ao plano de contas ou ao sistema operacional utilizado por eles;

e) Na prestação dos serviços de leasing financeiro o Imposto Sobre Serviços deve ser recolhido no local em que está o poder decisório para efetivar a prestação desse serviço, que pode ser o local do estabelecimento prestador em que ele é oferecido;

f) O poder decisório para aprovar o leasing financeiro não é absoluto, seu exercício encontra-se condicionado à observância das normas inscritas no 
Revista da ESDM - 2016 - V. 2 - n. ${ }^{\circ} 3$

Código de Defesa do Consumidor e, em princípio, ele se esgota com a oferta, podendo ser suprida judicialmente a vontade que o manifesta no foro do domicílio do tomador (= consumidor), conforme facultado no artigo 101, I, do Código de Defesa do Consumidor;

g) A nulidade da Certidão de Dívida Ativa (CDA) somente pode ser cogitada nos casos em que não preenchidos os requisitos arrolados no artigo 202 do Código Tributário Nacional ou comprovada a ocorrência de dano à defesa.

Com essas considerações espera-se contribuir para melhorar o contexto que envolve o tema objeto de estudo.

\section{NOTAS}

1. No site do Sindicato dos Servidores do Banco Central (www.sinal.org.br) pode-se encontrar dados interessantes sobre esse tema, em especial, no texto A Regulamentação do Artigo 192: Desenvolvimento e Cidadania.

2. Texto ESPÉCIES TRIBUTÁRIAS, distribuído no Curso de Especialização em Direito Tributário da PUCRS, em 20/04/2012.

\section{REFERÊNCIAS BIBLIOGRÁFICAS}

ÁVILA, Humberto. Sistema Constitucional Tributário. 2. a ed. São Paulo: Saraiva, 2006.

BALEEIRO, Aliomar. Direito Tributário Brasileiro. Rio de Janeiro: Forense, 2000.

BARRETO, Aires Fernandino. ISS - Atividade-meio e Serviço-fim. Revista Dialética de Direito Tributário vol. 5, São Paulo: Dialética, 1996. 
CALIENDO, Paulo. Direito Tributário - Três Modos de Pensar a Tributação - Elementos para uma Teoria Sistemática do Direito Tributário. Porto Alegre: Livraria do Advogado, 2009.

GRAU, Eros Roberto. O Direito posto e o Direito Pressuposto; São Paulo: Malheiros; 1996.

LESSA, Sérgio. Para Além de Marx? Crítica da teoria do trabalho imaterial. São Paulo: Ed. Xama, 2005.

SCHOUERI, Luís Eduardo. Livre Concorrência e Tributação. In: ROCHA, Valdir de Oliveira. (Org.) Grandes Questões Atuais do Direito Tributário, v. 11. São Paulo: Dialética.

SOARES DE MELLO, José Eduardo. ISS - Aspectos Teóricos e Práticos. São Paulo: Dialética, 2005. 